\title{
EVALUATION OF CD82/ (KAI-1) IMMUNOHISTOCHEMICAL EXPRESSION IN COLORECTAL CARCINOMA
}

\author{
By
Anass Fathi Shafiq Al-Gazzar, Sayed Abd El-Raheem Sayed Ali and Al- Sayed Mohammed Ibrahim Tealeb \\ Department of Pathology, Faculty of Medicine, Al-Azhar University \\ E-mail: doctoranass88@gmail.com
}

\begin{abstract}
Background: Colorectal carcinoma (CRC) is one of the most common human cancers. It is the fourth most common cause of death from cancer. Colorectal cancer is the third most common cancer in men and the second in women worldwide.

Objective: To evaluate the immunohistochemical expression of KAI-1/CD82 in different stages of colorectal carcinoma and to evaluate the biological behavior of tumor and target therapy.

Patients and Methods: Thirty formalin-fixed, paraffin-embedded tissue of colorectal carcinoma (obtained from archive of Al-Azhar University Hospital Labs and some private labs). Clinicopathological and histological features were taken from files and confirmed by H\&E examination. Immunohistochemical study was done by using CD82/ (KAI-1) marker.
\end{abstract}

Results: CD82 showed an insignificant relation with age, sex, site of tumor and degree of differentiation. A significant inverse relationship was detected between CD82 expression in tumor cells and tumor stage according to modified Duke's staging. Insignificant relation between age, sex, site and grade.

Conclusion: The decreased membranous and/or cytoplasmic expression of CD82 might be used as a prognostic marker to monitor patient with colorectal cancer.

Keywords: CD82, KAI1, Colorectal carcinoma.

\section{INTRODUCTION}

Colorectal carcinoma (CRC) is one of the most common human cancers. It is the fourth most common cause of death from cancer. Colorectal cancer is the third most common cancer in men and the second in women worldwide (Ferlay et al., 2010).

Colorectal cancer (CRC) is the 4th most common leading cause of cancerrelated mortality in the world, accounting for approximately $10 \%$ of all human cancers (Zavarhei et al., 2014).
Early diagnosis of CRC, successful surgical treatment contributed to better outcome of affected patients. Therefore, identification of molecular marker associated with carcinogenesis, tumor growth, invasion and metastasis have been critical to developing potential therapeutic intervention (Doger et al., 2012).

Immunohistochemical marker of our study (KAI-1)/CD82 was first identified as a metastasis suppressor gene which is located in human chromosome 11p and it is a member of the transmembrane 4 
superfamily (TM4SF). KAI-1 can regulate signal transduction both cells to cells and cells to extracellular matrix (ECM) and involved in some fundamental biological processes such as fusion, migration, adhesion, differentiation, and invasion. Accumulating evidence has demonstrated that decreased or lost KAI-1 expression should associate the metastasis and prognosis in various tumors, including laryngeal carcinoma, prostate carcinoma, breast carcinoma, lung carcinoma, gastric carcinoma, colon carcinoma, and hepatocellular carcinoma (Petrelli et al., 2016).

The present work aimed to evaluate the immunohistochemical expression of KAI-1/CD82 in different stages of colorectal carcinoma, and to evaluate the biological behavior of tumor and target therapy.

\section{PATIENTS AND METHODS}

This work included 30 cases of colorectal carcinoma obtained through collection of archived paraffin blocks of colectomy operation for cases of colorectal carcinoma, from the Pathology Department, Faculty of Medicine, AlAzhar University during the period from June 2010 till December 2018 and some private labs achieves. The study was approved by the Ethics Board of Al-Azhar University. Clinicopathological and histological data were obtained from patient file and confirmed by $\mathrm{H} \& \mathrm{E}$ examination. Cases of our study staging done according to modified Duke's staging (Akkoca et al., 2014). All cases were conventional colorectal adenocarcinoma. In according to modified Duke's staging; 3 out of 30 cases $(10 \%)$ Duke's stage A, 4 out of 30 cases (13.3\%) stage B1, 5 out of 30 cases (16.6\%) stage B2, 9 out of 30 cases (30\%) stage $\mathrm{C} 1$ and 9 out of 30 cases $(30 \%)$ stage C2. By applying WHO classification (2019) cases graded as 9 cases $(30 \%)$ grade I, 18 cases $(60 \%)$ grade II, 3 cases (10\%) grade III.

\section{The paraffin embedded blocks for each case was cut and subjected to:}

1. Routine hematoxylin and eosin staining to confirm the original diagnosis and to revise grade and stage.

2. Immunohistochemical staining for CD82/ (KAI-1) marker.

\section{Procedure of immunostaining:}

Avidin-Biotin immunoperoxidase Complex technique (ABC) was used:

1. Deparaffinization and rehydration: Paraffin embedded tissues were deparaffinized and rehydrated through graded alcohol series.

2. Antigen retrieval: Tissue sections were treated in microwave oven for 5 minutes at $700 \mathrm{w}$, in ready to antigen retrieval citrate buffer, and then sections were left to cool.

3. Slides with the sections were stuck to cover plates using phosphate buffered saline (PBS), $\mathrm{pH} \quad 7.6$ for immunostaining steps.

4. Peroxidase blocking by adding 2 drops of peroxidase blocking serum for 10 minutes, then rising with $\mathrm{PBS}, \mathrm{pH}$ 7-6 was done.

5. Serum blocking by adding two drops of protein blocking serum for 10 minutes. No rinse after this step.

6. Addition of the primary antibody by adding two drops to each section and 
incubating in moist chamber for 30 minutes at room temperature.

7. Addition of the link by adding 2 drops of the pre-diluted biotinylated secondary antibody to each section for 45 minutes, then rinsing with PBS was done.

8. Addition of the label by adding 2 drops of the horse radish peroxidase conjugated streptavidin followed by incubation for 20 minutes. Then rinsing with PBS was done.

9. Addition of substrate/ chromogen (DAB) mixture (which was prepared immediately before use) by adding 2 drops and incubating for 5-10 minutes followed by rinsing with distilled water.

10. Counterstaining with Harris's hematoxylin was done.

11. The sections were dehydrated with graded alcohol series, cleared in xylene and finally mounted by DPX then slide cover was put.

\section{Positive control:}

Normal mucosal lining included in colectomy spicemens were used as positive control for CD82 immunostaining.

\section{Evaluation of Cd82 immunostaining:}

To assess CD82 expression, tumor tissue sections were examined and scored under the microscope starting at low power then higher power magnification, for the presence of membranous and/or cytoplasmic staining in tumor cells. Both the extent and intensity of immunostaining were thought. The staining intensity score was graded as follows: none 0 ; weak 1 ; moderate 2 ; and strong 3. The extent of positive staining was graded as follows: $<25 \%, 1 ; 25-50$ $\%, 2$; and $>50 \%, 3$. The score was determined by multiplying the extent and intensity of immunostaining to reach a range of scores from 0 to 9 . Immunostaining was thought positive when the score was $>3$ (Ohe et al., 2012). The results of CD82 immunostaining in tumor cells were correlated with multiple prognostic factors (age, sex, and site of the tumor, degree of differentiation and staging of tumors according to modified Duke's classification).

\section{Statistical analysis:}

SPSS version 18.0 was used for data analysis. Mean \pm standard deviation described quantitative data. Qualitative data were expressed as percentages. Percentages were compared using Chisquare and Fisher-exact tests. When $\mathrm{P}$ value levels were found to be less than 0.05 , the results were considered to be statistically significant. 


\section{RESULTS}

Thirty cases of colorectal carcinoma obtained through collection of archived paraffin blocks of colectomy operation for cases of colorectal carcinoma, from the Pathology department, Faculty of medicine, Al- Azhar University during the period from June 2010 till December 2018 and some private labs archieve.
Ages of the patients ranged from 23 to 80 years with mean age 51.50 \pm 12.27 years. All cases were conventional adenocarcinoma different grades and stages. According to age of the cases included in the study mostly were above 40 years old 25 cases (83\%) and 5 cases $(17 \%)$ less than 40 years old (Table 1).

Table (1): Distribution of cases according to age and gender

\begin{tabular}{|c|c|c|c|}
\hline \multirow{2}{*}{ Age } & & Count & Percentage \\
\hline \multirow{2}{*}{ Gender } & Above 40 years & 25 & $83 \%$ \\
\cline { 2 - 4 } & Less than 40 years & 5 & $17 \%$ \\
\cline { 2 - 4 } & Male & 18 & $60 \%$ \\
\cline { 2 - 4 } & Female & 12 & $40 \%$ \\
\hline
\end{tabular}

As regard relation between age of cases and CD82 expression 25 of selected cases were $>40$ years old showing 19 case (76\%) positive for stain and 6 cases (24\%) negative for stain, 5 of selected cases were $<40 y$ showing 3 cases $(60 \%)$ negative for stain and 2 cases (40\%) positive for staining P-value $=0.109>0.05$ considered insignificant and so, there is no relationship between age and CD82 expression (Table 2).

Table (2): The relationship between CD82 expression and age.

\begin{tabular}{|c|c|c|c|c|}
\hline Age & No. of cases & Reactivity & No. of cases & Percentage \\
\hline \multirow{2}{*}{$>40 \mathrm{Y}$} & \multirow{2}{*}{25} & Negative & 6 & $(24 \%)$ \\
\cline { 2 - 5 } & & Positive & 19 & $(76 \%)$ \\
\hline \multirow{2}{*}{\begin{tabular}{c} 
Y \\
\cline { 2 - 4 }
\end{tabular}} & Negative & 3 & $(60 \%)$ \\
\cline { 2 - 5 } & Positive & 2 & $(40 \%)$ \\
\hline \multicolumn{5}{|c}{ P-value $=0.109$} \\
\hline
\end{tabular}

In this study as regard relation between grade and CD82 expression, cases sub classified as; 18 out of 30 cases; grade II showed 13 cases $(72.2 \%)$ positive for stain and 5 cases $(27.8 \%)$ negative for stain, 9 out of 30 cases $(30 \%)$ grade I showed7cases $(77.8 \%)$ positive for stain and 2 cases $(22.2 \%)$ negative for stain, 3 out of 30 cases $(10 \%)$ grade III showed 2cases $(66.7 \%)$ negative for stain and one case $(33.3 \%)$ positive for stain with $\mathrm{P}$ value $=0.329$ revealed insignificant relation between tumor grade and CD82 immunostain expression (Table 3). 
Table (3): Relation between CRC grade and CD82expression

\begin{tabular}{|c|c|c|c|c|}
\hline Grade & No. of cases & Reactivity & No. of cases & Percentage \\
\hline \multirow{2}{*}{ Grade1 } & \multirow{2}{*}{9} & Negative & 2 & $22.2 \%$ \\
\cline { 3 - 5 } & \multirow{2}{*}{ Grade 2} & Positive & 7 & $77.80 \%$ \\
\hline \multirow{2}{*}{ Grade 3 } & Negative & 5 & $27.8 \%$ \\
\cline { 2 - 5 } & \multirow{2}{*}{3} & Positive & 13 & $72.2 \%$ \\
\cline { 2 - 5 } & Negative & 2 & $66.7 \%$ \\
\hline \multicolumn{5}{|c|}{ P. value 0.329 } \\
\hline
\end{tabular}

In this study as regard relation between stage of CRC and CD82 immunostain expression; 3out of 30 cases (10\%) Duke's stage A showed 3 cases $(100 \%)$ positive for stain. 4 out of 30 cases $(13.3 \%)$ stage B1were all positive for stain. 5 out of 30 cases $(16.6 \%)$ stage B2 showed all cases positive for stain. 9 out of 30 cases $(30 \%)$ stage $\mathrm{C} 1$ showed 6 cases $(66.7 \%)$ positive and 3 cases $(33.3 \%)$ negative. 9 out of 30 cases $(30 \%)$ stage $\mathrm{C} 2$ showed 6 cases
(66.7\%) negative and 3 cases $(33.3 \%)$ positive for stain with $\mathrm{P}$-value $=0.027$ revealed significant relation between CRC stage and CD82 immunostain expressions as decreased Expression of CD82 in CRC Significantly Associate with tumor invasion and lymph node Metastasis demonstrating inverse relationship between degree of CD82 expression and tumor stage (Table 4).

Table (4): Relation between CRC stage and CD82expression

\begin{tabular}{|c|c|c|c|c|}
\hline Stage & No. of cases & Reactivity & No. of cases & $\%$ \\
\hline \multirow{2}{*}{ Stage A } & \multirow{2}{*}{3} & Negative & - & - \\
\hline & & Positive & 3 & $100 \%$ \\
\hline \multirow{2}{*}{ Stage B1 } & \multirow{2}{*}{4} & Negative & - & - \\
\hline & & Positive & 4 & $100 \%$ \\
\hline \multirow{2}{*}{ Stage B2 } & \multirow{2}{*}{5} & Negative & - & \\
\hline & & Positive & 5 & $100 \%$ \\
\hline \multirow{2}{*}{ Stage C1 } & \multirow{2}{*}{9} & Negative & 3 & $33.3 \%$ \\
\hline & & Positive & 6 & $66.7 \%$ \\
\hline \multirow{2}{*}{ Stage C2 } & \multirow{2}{*}{9} & Negative & 6 & $66.7 \%$ \\
\hline & & Positive & 3 & $33.3 \%$ \\
\hline
\end{tabular}



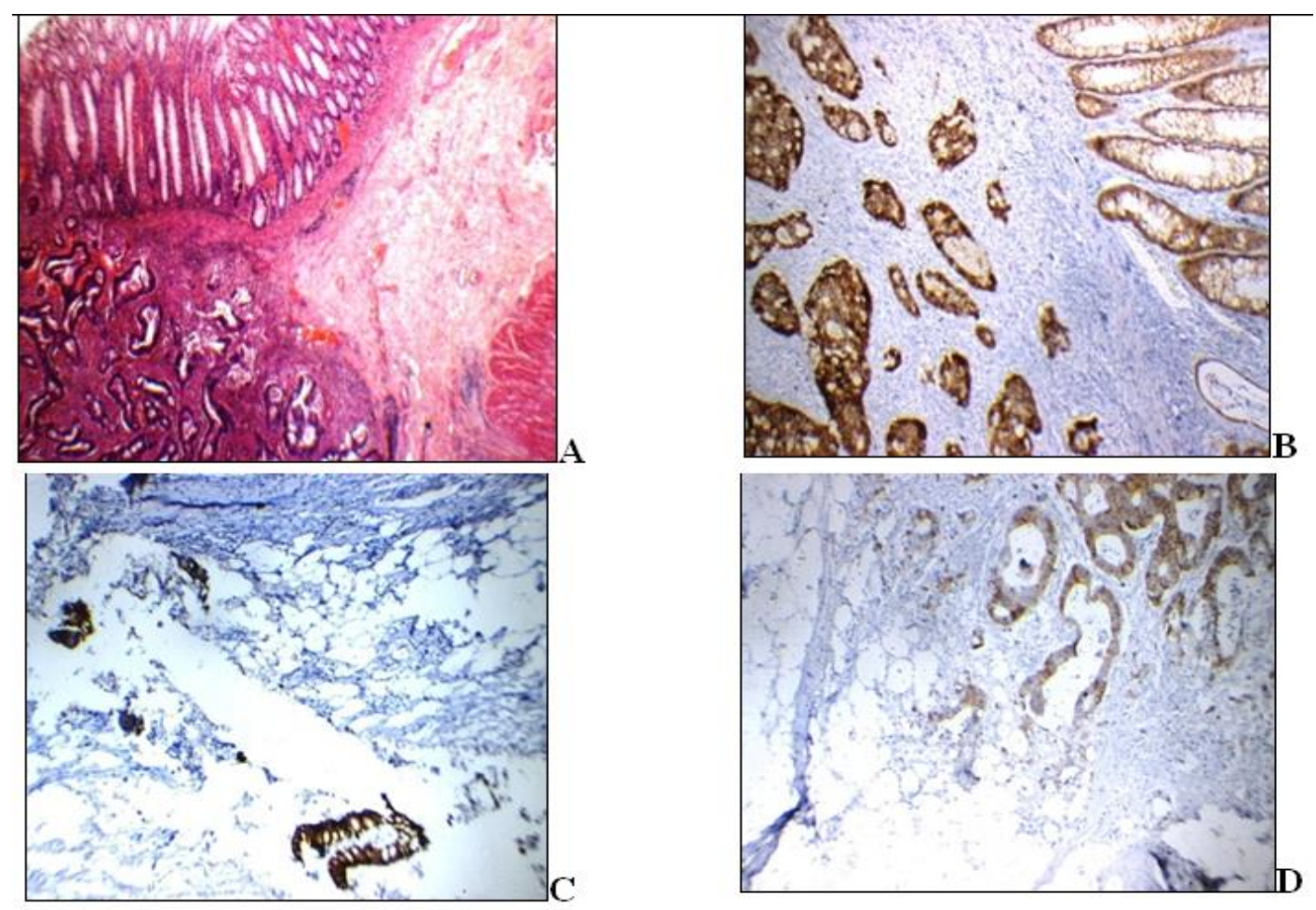

Figure (1): A; CRC showing moderately differentiated malignant acini (grade II) infiltrating muscularis mucosa not reaching the muscle (Duke's stage A), (H\&E X 100). B; immunostain of previous slide showing strong reactivity (+3) for CD82 in case of moderately differentiated adenocarcinoma, (Duke's stage A), with reactivity normal mucosa served as positive control (CD 82 immunostain X 200). C; CRC showing negative reactivity for CD82 in case of moderately differentiated adenocarcinoma, (Duke's stage C1), (lost pattern), (CD 82 imunostain X 200). D; CRC grade II, stage B1 CD82 immunostaining showing positive strong exepression of CD82 (+3) (CD 82 immunostain X 200).

\section{DISCUSSION}

In this study, the age of cases of CRC ranged from 23 to 80 years with a mean age of $51.50 \pm 12.27$ year.

As regard the relation between age of patient and CD82 immunostain expression, 25 out of $83.3 \%$ who were $>40$ years old showed $76 \%$ positive for stain and $24 \%$ negative for stain. Five out of 30 cases who were $<40$ years old showed $40 \%$ positive, and $40 \%$ negative, revealed insignificant relation between age and CD82 immunostain expression.
This was in agreement with Ganji et al. (2018) who found that age ranged from 35 to 91 years old in the study showed $77.2 \%$ positive and $22.8 \%$ negative while $26.6 \%$ $<40$ years old showed $75 \%$ negative, and $25 \%$ positive revealed insignificant relation between age and CD82 immunostain expression.

As regard relation between tumor site and CD82 expression considered insignificant. So, there was no relation between tumor site and CD82 imunostain expression. This was in agreement with Liu et al. (2014). 
In the current study, as regard the immunohistochemical expression of CD82, 76.7\% showed positive expression for CD82 have more than score 3 of immunostain expression in the cell membrane and/or cytoplasm with variable intensity of stain $(+5$ mild, +7 moderate, +9 strong) while $23.3 \%$ of the studied cases showed negative expression of CD82 showed score $<3$ classified as lostpattern (negative). Near results were obtained by Lee et al, (2019).

In this study, as regard relation between CD82 expression and tumor grade, came in 1st rank grade II, $60 \%$ from total cases showing $72.2 \%$ positive for stain and $27.8 \%$ negative for stain. Came in $2^{\text {nd }}$ rank grade $\mathrm{I}, 30 \%$ from total cases showing $77.8 \%$ positive for stain and $22.2 \%$ negative for stain. Less percent were grade III, $10 \%$ from total cases showing $66.7 \%$ negative for stain and $33.3 \%$ positive for stain with considered insignificant and so, there is no relation between tumor grade and CD82immunostainexpression.

This was in agreement with Zhu et al. (2017). The relation between CD82 expression and tumor stage came in 1st rank Duke's stage C 30\% from total cases sub classified as stage $\mathrm{C} 166.7 \%$ positive for stain and $33.3 \%$ negative for stain , C2 $66.7 \%$ negative for stain and $33.3 \%$ positive for stain. Came in 2nd rank Duke's stage B $30 \%$ from total cases sub classified as stage B1 4 cases all were positive for stain with variable intensity and stage B2 5 cases all positive for stain with different intensity. Less percent were Duke's stage A $10 \%$ from total cases all were positive for stain with variable intensity were significant as CD82 immunostain expressions in Duke's A were higher than Duke's B carcinoma and both were higher compared to Duke's $\mathrm{C}$ carcinoma.

This revealed that decreased expression of CD82 in colorectal cancer significantly associate with tumor invasion and lymph node metastasis demonstrating inverse relationship between degree of CD82 expression and tumor stage. This was in agreement with Ganji et al. (2018).

\section{CONCLUSION}

1. The decreased expression of CD82 might be used as a prognostic marker to monitor patient with colorectal cancer.

2. CD82 expression of tumor cells may be used as a tool to evaluate life expectancy, response to the treatment, metastatic disease and recurrence of the tumor.

3. CD82 expression in colorectal carcinoma has no correlation to tumor site, patient's sex, age or degree of differentiation of the tumor.

Acknowledgement: We would like to thank the Pathology Department of AlAzhar Faculty of Medicine. We are also indebted to our colleagues for their cooperation in this research.

\section{REFERENCES}

1. Akkoca AN, Yanık S, Özdemir ZT, Cihan FG, Sayar S, Cincin TG and Özer C. (2014): TNM and Modified Dukes staging along with the demographic characteristics of patients with colorectal carcinoma. International Journal of Clinical and Experimental Medicine, 7(9): 2828-35.

2. Doger $K$, Meteoglu $I$ and Tuncyurek $P$ (2012): The EGFR \& VEGF expression 
predicts the prognosis in colon cancer. Eur Surg Res., 38: 540-544.

3. Ferlay J, Shin HR, Bray F, Forman D, Mathers C and Parkin DM (2010): Cancer Incidence and Mortality Worldwide Int $\mathrm{J}$ Cancer, 136(5):E359-86.

4. Ganji S, Saligheh A, Shafiepour S, Ashrafi F and Pornour M. (2018): Decreased expression of KAI1 in colorectal cancer significantly associates with the cancer metastasis. Journal of Research in Medical and Dental Science, 6(3): 78-84.

5. Lee MS, Lee J, Kim YM and Lee H. (2019): The metastasis suppressor CD82/KAI1 represses the TGF- $\beta 1$ and Wnt signalings inducing epithelial-to-mesenchymal transition linked to invasiveness of prostate cancer cells. Prostate, 79(12):1400-1411.

6. Liu L, Wu DH, Li ZG, Yang GZ and Ding YQ (2014): Effects of KAI1/CD82 on biological behavior of human colorectal carcinoma cell line. World Journal of Gastroenterology, 9(6): 1231-37.
7. Petrelli F, Tomasello G, Borgonovo K, Ghidini M, Turati L, Dallera P, Passalacqua R, Sgroi $G$ and Barni $S$. (2016): Prognostic Survival Associated With Left-Sided vs Right-Sided Colon Cancer: A Systematic Review and Meta-analysis. JAMA Oncol., 400-410.

8. Zavarhei MD, Bidgoli SA, Zryarani MM, Shariatpanahi M and Ardalan FA (2014): Progesterone receptor positive colorectal tumors have lower thymidine phosphory lase expression: An immunohistochemical study. Pak J Boil Sci., 10: 4485-4489.

9. Zhu B, Zhou L, Yu L, Song W, Gong $X$ and Wang D. (2017): Evaluation of the correlation of vasculogenic mimicry, ALDH1, KAI1 and microvessel density in the prediction of metastasis and prognosis in colorectal carcinoma. BMC Surg., 17(1):47-54. 


\section{تقييم سي دي 82 كصبغه مناعيه في حالات مرض سرطان القولون}

أنس فتحي شفيق الجزار، سيد عبد الرحيم سيد علي، السيد محمد إبراهيم تعيلب قسم الباثولوجيا العامهه، كلية طب، جامعة الأزهر

E-mail: doctoranass88@gmail.com

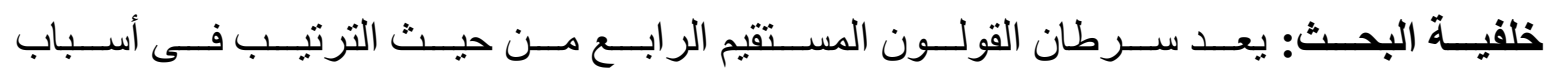

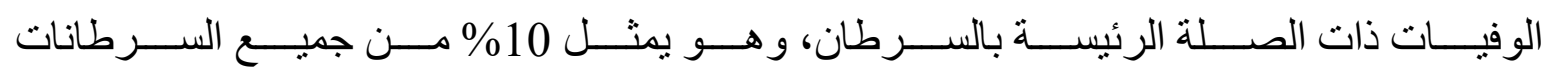

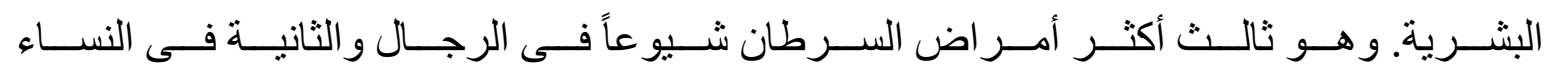
على مستوى العالم.

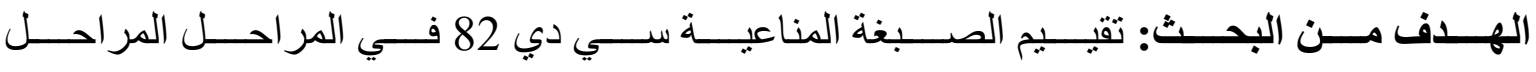

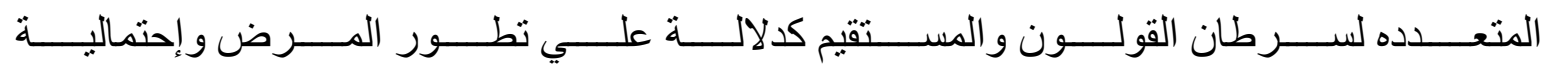
إستخدامه في تحديد طرق العلاج.

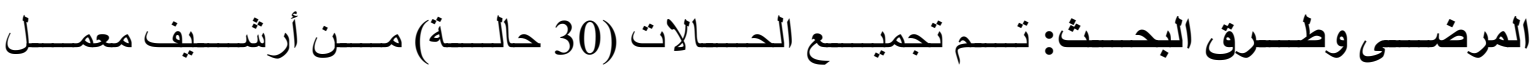

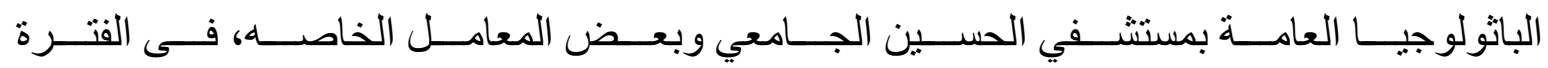

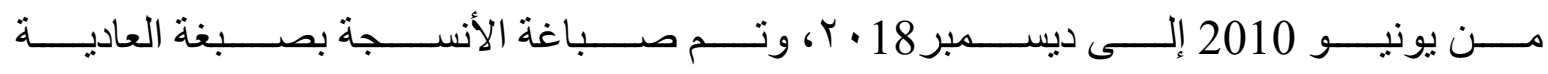

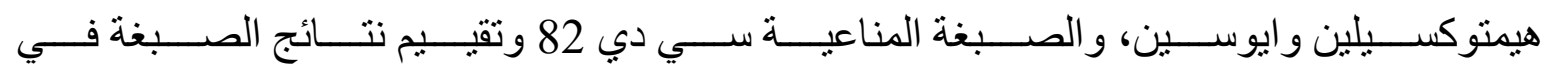
المر احل المختلفة تبعا لنظام ديوكس.

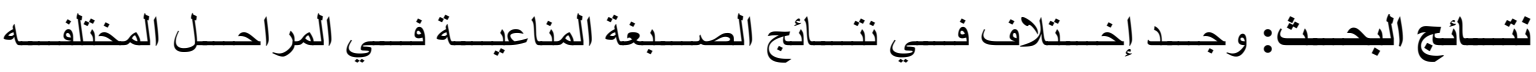

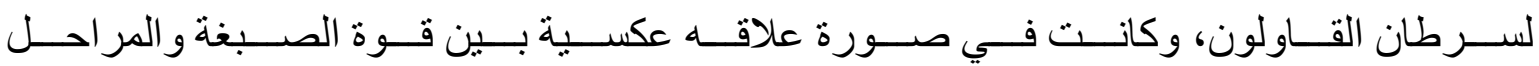

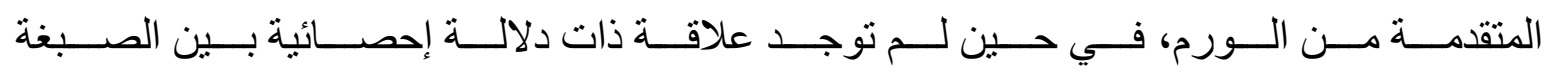
المناعية ودرجة تمنيز الورم و النوع و العمر ومكان الورم بالقولون.

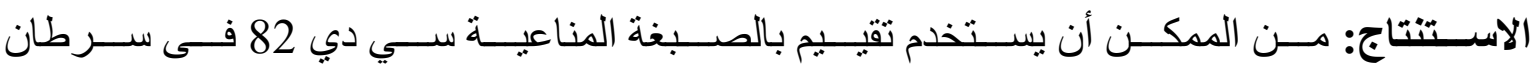
القولون كدلالة علي تطور المرض و إنتشارة وتحديد طرق العلاج المناسبة. الكلمات الدالة: سرطان القولون، سى دى 82. 